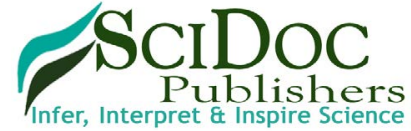

International Journal of Anesthesiology \& Research (IJAR)

ISSN 2332-2780

\title{
Comparative Study of Epidural Dexmedetomidine and Magnesium Sulphate used as Adjuvant to Ropivacaine for Post-Operative Analgesia in Thoracotomy
}

Research Article

Kumar Paswan A

Associate Professor, Department of Anesthesia, IMS, BHU, Varanasi, India.

Abstract

Background: Dexmedetomidine is the selective 2-adrenoceptor agonist with analgesic potency. Magnesium has antinociceptive effects in animal and human models of pain. Our hypothesis was that the addition of magnesium and dexmedetomidine to thoracic epidural bolus of ropivacaine may increases the duration of analgesia.

Methods: Sixty patients undergoing thoracotomy were enrolled to receive either dexmedetomidine(Group D) or magnesium sulphate (Group M) till first epidural top up. In Group D, patients received $1 \mu \mathrm{g} / \mathrm{kg}$ dexmedetomidine +ropivacaine $0.375 \%$ and group $\mathrm{M}$ patients received magnesium sulphate $75 \mathrm{mg}$ +ropivacaine $0.375 \%$ epidurally as an initial bolus dose. Pain assessment using a visual analogue scale (VAS), Time to reach maximum sensory block level, Sensory block level, first epidural top, heart rate, blood pressure sedation scores were observed in the postoperative period. In post - operative monitoring, any untoward complications like hypotension, hypertension, bradycardia, tachycardia, nausea, vomiting, respiratory depression were also observed.

Results: The demographic profile of patients was comparable in both the groups. Time to reach maximum sensory block level in group D vs M $(16.30 \pm 4.27$ vs. $14.28 \pm 3.38)$ was significantly earlier in the M group. Postoperative analgesia was prolonged significantly in the $\mathrm{D}$ group $(8.00 \pm 1.01)$ as compare to group $\mathrm{M}(5.27 \pm 0.69)$. Sedation scores were noted $<3$ in the group D. While the incidence of dry mouth, decrease heart rate significantly were higher in the $\mathrm{D}$ group. Incidence of nausea and vomiting, respiratory depression were similar in both group.

Keywords: Epidural Analgesia; Thoracotomy; Dexmedetomidine; Magnesium Sulphate.

\section{Introduction}

Post-thoracotomy pain management plays an very essential role in the outcome of thoracic surgery for lung resection. Use of Highdose opioids are for treating intense postoperative pain associated with many side effects. Regional anaesthesia is a safe, inexpensive technique, with the advantage of prolonged postoperative pain relief. Effective treatment of postoperative pain blunts autonomic, somatic, and endocrine responses. It has become common practice to use a polypharmacological approach for the treatment of postoperative pain, because no drug has yet been identified that specifically inhibits nociception without associated side-effects. Research continues concerning different techniques and drugs that could prolong the duration of regional anaesthesia and postoperative pain relief. There are multiple literature and studies has shown that dexmedetomidine is agonist of alpha-2 adrenergic receptors and indicated for sedation in ICU setting, postoperative pain either by I.V. or regional anesthesia.

The exact mechanism of magnesium on analgesia is not clear, and the study results are still controversial. Noxious stimulation causes release of excitatory amino acids such as glutamate and aspartate mediated by NMDA and non-NMDA receptors [1, 2]. Magnesium is a natural calcium antagonist, has been reported as an adjuvant to analgesics in the perioperative period $[2,3]$. Kroin et al reported that intrathecal magnesium enhances opioid antinociception in an acute incisional model [3]. These effects have prompted the investigation of magnesium as an adjuvant for postoperative analgesia. There are studies concerning different routes of magnesium administration such as i.v. or intrathecally, that improve anaesthetic and analgesic quality $[4,5]$. Very minimal clinical studies have examined the effect of administered epidurally magnesium and dexmedetomidine. We therefore

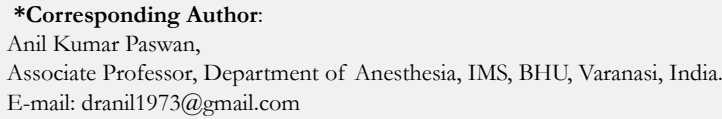

Citation: Kumar Paswan A (2016) Comparative Study of Epidural Dexmedetomidine and Magnesium Sulphate used as Adjuvant to Ropivacaine for Post-Operative Analgesia in Thoracotomy. Int I Anesth Res. 4(5), 239-243. doi: http://dx.doi.org/10.19070/2332-2780-1600054

Copyright: Kumar Paswan $\mathbf{A}^{\circ}$ 2016. This is an open-access article distributed under the terms of the Creative Commons Attribution License, which permits unrestricted use, distribution and reproduction in any medium, provided the original author and source are credited. 
conducted a prospective, randomized, controlled clinical trial with a hypothesis that the epidural injection of dexmedetomidine and magnesium to ropivacaine increases the duration of postoperative analgesia/ first epidural top up.

\section{Methods}

After approval from institutional ethical committee, 60 patients, ASA physical status II-III, scheduled for elective pulmonary surgery, gave their written informed consent to participate in this prospective, controlled, double blind randomized study. All patients required thoracotomies for various surgeries like decortication, lobectomy, excision of hydatid cyst in the lateral decubitus position and one-lung ventilation. Total pneumonectomy were excluded from this study. Preoperative history, clinical examination, pulmonary function tests, laboratory results, electrocardiogram, chest radiograph, were noted.

Before induction of anesthesia hemodynamic monitoring was established with a radial artery catheter contralateral to the operated side for invasive blood pressure monitoring, arterial blood gas sampling and hemoglobin determinations. Heart rate, arterial blood pressure, arterial oxygen saturation $\left(\mathrm{Spo}_{2}\right)$ by pulse oximetry, electrocardiogram, oropharyngeal temperature, inspired oxygen fraction and end-tidal isoflurane concentration as well as end-tidal $\mathrm{CO}_{2}$ monitored continuously. All patients received 0.5 mg alprazolam orally $2 \mathrm{~h}$ before their arrival in the operating room. Anesthesia was induced in both groups with IV doses of propofol $(2-3 \mathrm{mg} / \mathrm{kg})$, fentanyl (2-3 $\mu \mathrm{g} / \mathrm{kg})$, and vecuronium $(0.1 \mathrm{mg} / \mathrm{kg})$ and maintained with an end-tidal concentration of 1-2 vol \% isoflurane. After induction of anesthesia, a leftsided double-lumen tube was inserted. The correct position of the tube was determined by auscultation and confirmed by fiberoptic bronchoscopy before and after the patient was in the lateral decubitus position. After induction and loss of resistance technique epidural catheter was placed at the T6-7 or T7-8 interspace with $18 \mathrm{G}$ epidural needle using the paramedian approach. The patients' lungs were ventilated with intermittent positive pressure. Ventilation was controlled with $\mathrm{FiO}_{2}$ 0.5-1.0 and a tidal volume of $7-10 \mathrm{~mL} / \mathrm{kg}$ a to maintain Etco2 in the range of 35 to $45 \mathrm{~mm} \mathrm{Hg}$. Erythrocyte transfusions were administered to maintain a hemoglobin level of $10 \mathrm{~g} / \mathrm{dL}$. Volume treatment was controlled in both groups with crystalloids and colloids to keep the patient in stable fluid balance.

After closing and dressing of the surgical wound, patient made supine from lateral surgical position and extubated after adequate reversal. Patients were shifted to post-operative room and monitored. Once the patient in the post-operative room was noted to have pain (visual analogue scale (VAS) of $>3$ ), the study started. A test dose of $3 \mathrm{ml}$ lidnocaine with adrenaline $(1: 200,000)$ was injected and the patients were randomly allocated to one of the following two groups in a double-blinded fashion based on a computer-generated code: Group D ( $=30)$ : Received ropivacaine $0.375 \% 8 \mathrm{ml}(1.5 \mathrm{ml} /$ segment $)$ plus dexmedetomidine $1 \mathrm{mcg} / \mathrm{kg}$ and group $\mathrm{M}(\mathrm{N}=30)$ : Received ropivacaine $0.375 \%$ $8 \mathrm{ml}$ plus magnesium sulphate $75 \mathrm{mg}$. After administering the drug, the following parameters were noted by the independent observer. (1) The pain score, by using VAS until the need for next epidural top. The level of anesthesia was determined by loss of pinprick sensation (3) Peak level of analgesia (achieving VAS score
0). (4) First Epidural top up/duration of analgesia (epidural drug administration to once the patient asks for additional epidural analgesia with VAS $>3$ ). (5) Observation of vital parameters such as IBP, pulse rate (6) Side-effects such as hypertension / hypotension, respiratory depression, nausea- vomiting, sedation (Ramsay sedation scale), pruritis and dry mouth. Once the patient asked for additional epidural analgesia (VAS $>3$ ) for pain relief during the observation period, the study terminated and the above mentioned parameters were noted. Hypotension was treated with injection ephedrine $5 \mathrm{mg}$ IV bolus and heart rate $<50$ beats $/ \mathrm{min}$ was treated with $0.01 \mathrm{mg} / \mathrm{kg}$ of injection atropine. Post-operative maintenance IV fluids were given as per body weight. Nausea and vomiting were treated with $0.1 \mathrm{mg} / \mathrm{kg}$ of IV ondansetron.

\section{Statical analysis}

Chi-square test was used to compare the two groups of qualitative test and t-test was used for quantitative data by Statistical Package for Social Science version 20. Data are expressed as mean \pm SD. Value of $P<0.05$ is considered significant. The minimal sample size was 60 by $\alpha$ (type I error) of 0.05 with power of study $80 \%$.

\section{Result}

There was no statistically significant difference between the two groups in any of the demographic data.

There was statistical significance between the two groups as regards the time to reach peak sensory level, time to first epidural top up was significantly shorter in $\mathrm{M}$ group than the $\mathrm{D}$ group $(8.00 \pm 1.01 \mathrm{vs} 5.27 \pm 0.69)$ means duration of analgesia was higher in group $\mathrm{D}$ as compare to group $\mathrm{M}$ and statistically significant as showed in Table 1 and Figure 1. Maximum segment level of sensory block was T3.

In group D; hypotension, bradycardia, pruritis sedation (ramsay sedation <3), and dry mouth were usual side effects. Almost all the tolerable side effects were most commonly found in dexmedetomidine group. No side-effects including nausea, vomiting, and respiratory depression were reported in either group. 15/30 patients showed decrease in heart rate in group D but none of them required atropine.

In both groups, Figure 1 showed the VAS score followed a decreasing trend from 0 to 20 min of post-epidural. From $20 \mathrm{~min}$ to $4 \mathrm{hr}$, the VAS score was zero and this period was totally pain free in group D. After 4 hrs, the VAS score showed an increasing trend. While in magnesium group VAS score was zero up to 2 hrs after that showed increasing trends of VAS. All the patients of either groups asked for additional epidural drug when the average VAS score was $>3$. M group needed epidural top up earlier than D group.

\section{Discussion}

Thoracotomies are painful operations, and well-planned pain management is crucial in decreasing morbidity after major thoracic surgery for lung resection. The main aim of postoperative analgesia is to provide patients comfort, in addition to inhibiting nociceptive impulse caused by surgical trauma and to blunt somatic as well as autonomic reflexes in response to pain. 
Table 1. Demographic Profile.

\begin{tabular}{|c|c|c|c|}
\hline Demographic Characteristics & D & M & P value \\
\hline Age in Years & $35.67 \pm 7.86$ & $35.43 \pm 7.01$ & 0.45 \\
\hline Weight in Kg & $59 \pm 8.14$ & $61 \pm 9.86$ & 0.34 \\
\hline Male / Female & $16 / 14$ & $20 / 10$ & 0.6 \\
\hline Mean duration of surgery & $120 \pm 10.5$ & $122 \pm 15.5$ & 0.21 \\
\hline ASA 2 \& 3 & $24 / 6$ & $27 / 3$ & 0.33 \\
\hline
\end{tabular}

$\mathrm{D}=$ Ropivacaine and Dexmedetomidine; $\mathrm{M}=$ Ropivacaine + Dexmedetomidine and magnesium sulphate

Figure 1. Visual analogue scale score (VAS) observation at different interval.

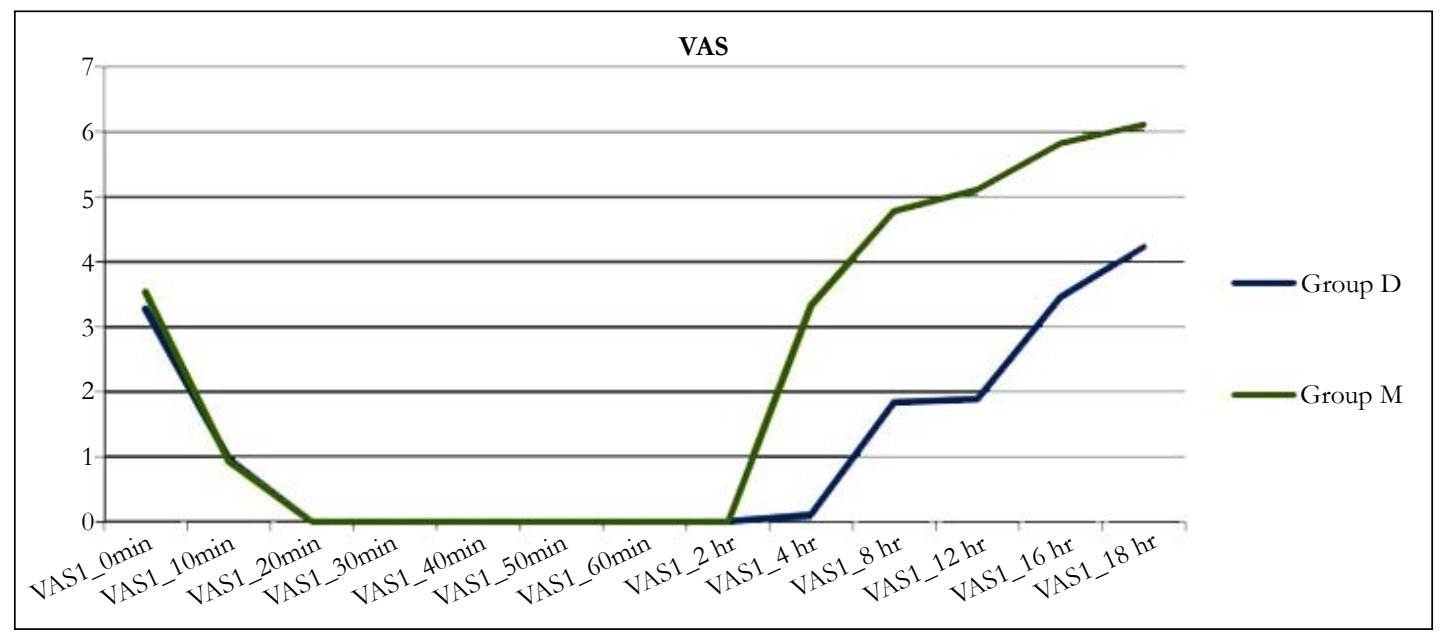

As multiple literature reported that when epidural local anesthetic dose is combined with an adjuvant as compared to local anesthesia alone provide superior pain relief, early mobilization, early chest physiotherapy and avoid pneumonia. Dexmedetomidine is highly lipid soluble and appears rapidly in CSF and has high binding affinity to a $\alpha 2$ receptors in the spinal cord used as adjuvant to regional anaesthetic drug provide analgesia, sedative properties and causes minimal respiratory depression $[6,7]$.

The synergistic effects between epidural dexmedetomidine and local anesthetics is well established but evidence regarding combination of ropivacaine with magnesium through epidural route is very scarce in literature.

In both the group demographic profile were comparable. We started the study with minimal pain (VAS $>3$ ). Time to reach peak effect of analgesia significantly earlier in M group as compare to dexmedetomidine group. However, mean VAS scores were higher in group $\mathrm{M}$ in comparison to group $\mathrm{D}$ at different time intervals hence first epidural top was earlier in group $\mathrm{M}$ as compare to group

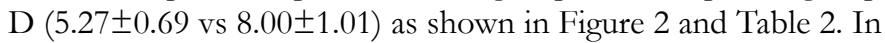
present study, epidurally magnesium $75 \mathrm{mg}$ and dexmedetomidine $1 \mathrm{mcg} / \mathrm{kg}$ added with ropivacaine mean duration of analgesia was significantly prolonged with dexmedetomidine as compared with magnesium but Billir et al [8] reported that co-administration of epidural magnesium $50 \mathrm{mg}$ with fentanyl $25 \mu \mathrm{g}$ for postoperative epidural analgesia provided a profound analgesia and reduction in patient-controlled epidural fentanyl consumption without any side-effects. Wider-Smith $\mathrm{O}$ et al reported that magnesium and ketamine inhibit the NMDA system differently [9]. Magnesium blocks calcium influx and non-competitively antagonizes NMDA receptor channels [10]. It is also possible mechanism is that magnesium analgesic effect occurred at the supra-spinal level and might be related to its systemic absorption and epidural usage may be related to the diffusion of magnesium from the duramater but ko et al [11] they reported that perioperative administration of magnesium did not increase CSF magnesium concentration. There are many studies the role of magnesium for postoperative analgesia. But most of these studies shown that systemic administration of magnesium is associated with smaller analgesic requirement and less discomfort in the postoperative period [12]. Ko and colleagues failed to observed postoperative analgesic effect with $50 \mathrm{mg} \mathrm{kg}^{-1}$ i.v. magnesium sulphate.

Intrathecal administration of magnesium has been demonstrated by Buvanendran and colleagues [13] in pregnant women that, if magnesium $50 \mathrm{mg}$ and fentanyl $25 \mu \mathrm{g}$ were given intrathecally, the median duration of analgesia was significantly prolonged compared with plain intrathecal fentanyl. Similarly, in another study by Ozalevli and colleague [14] reported that the addition of intrathecal magnesium $50 \mathrm{mg}$ to spinal anaesthesia prolonged the period of analgesia without any side-effects. Means, it is an effective analgesic when magnesium added to opioid either epidural or intrathecal.

The side-effect (Table 3) profiles of both groups of are quite favourable as none of the patient had profound deep sedation (ramsay sedation score $>3$ ) or respiratory depression. Postoperatively, HR and IBP lower side but remained stable throughout the study period in group dexmedetomidine and none of them require atropine or vasopressure, while in group magnesium there was not change in blood pressure and heart rate 
Figure 2. Heart rate in both groups.

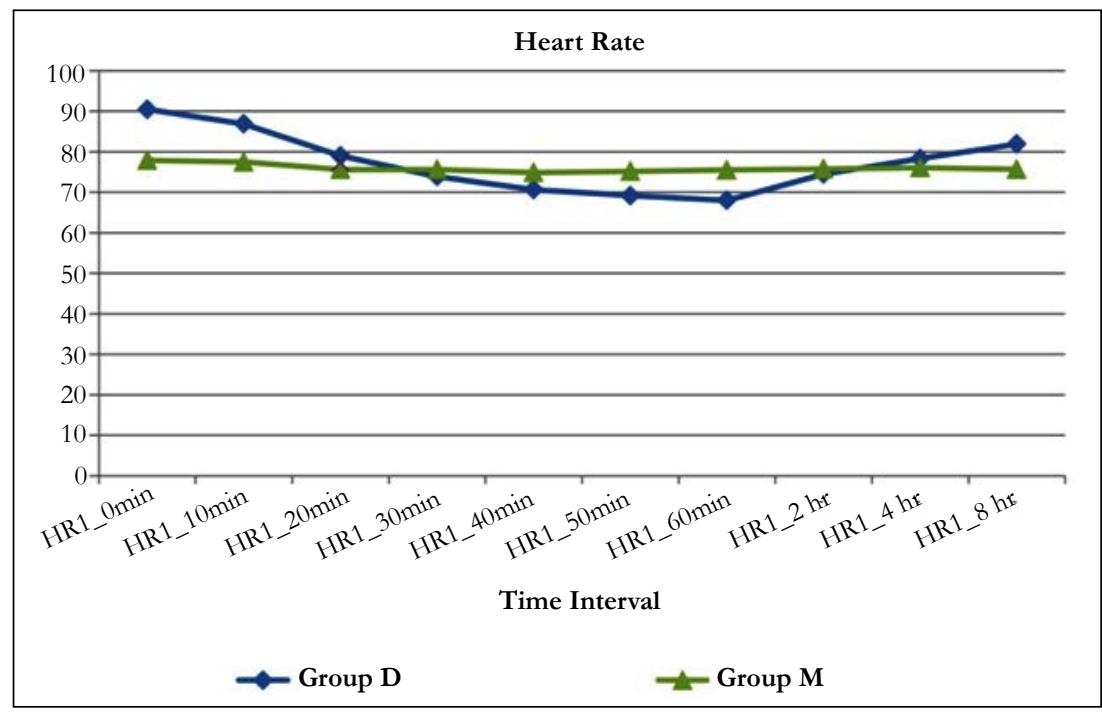

There was a decreasing trend of heart rate in group $\mathrm{D}$ but did not decrease in heart rate in group $\mathrm{M}$ at any time.

Table 2. Comparison of analgesics.

\begin{tabular}{|c|c|c|c|}
\hline Characteristic of Block & D & M & P \\
\hline Time to reach maximum sensory block level $(\mathrm{min})$ & $16.30 \pm 4.27$ & $14.28 \pm 3.38$ & 0.03 \\
\hline Sensory block level & T3-T4 & T3-T5 & \\
\hline First epidural top up in Hrs. (after VAS $>3)$ & $8.00 \pm 1.01$ & $5.27 \pm 0.69$ & 0.001 \\
\hline
\end{tabular}

Figure 3. Systolic and diastolic blood pressure(SBP \&DBP).

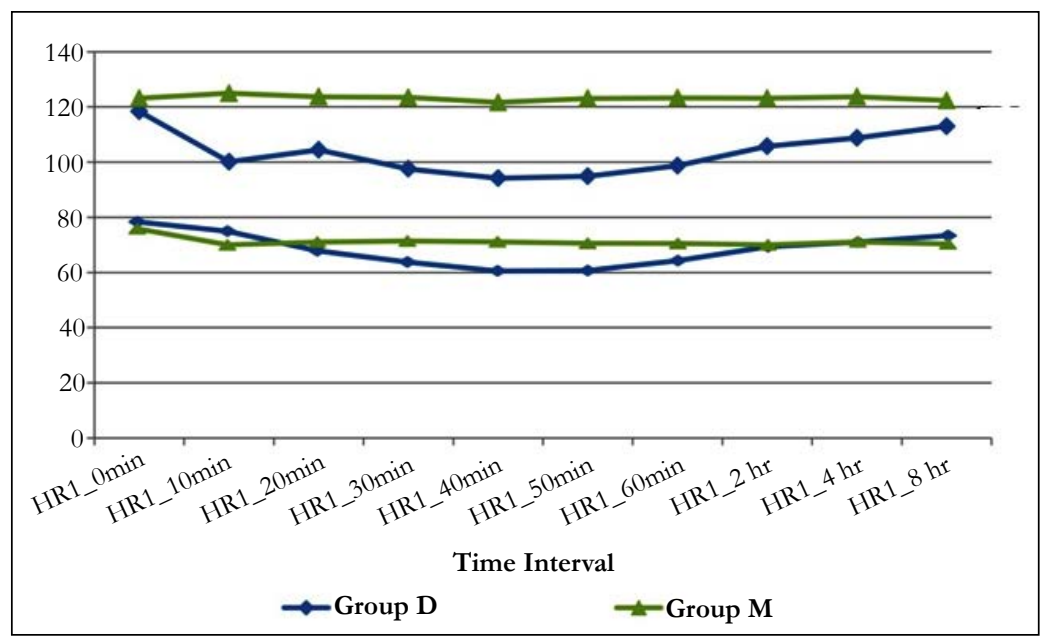

(Figure $2 \& 3$ ).

Bajwa et al [15] reported that analgesic properties, lower side blood pressure and decrease heart rate mostly due to their increased affinity to $\alpha-2$ receptors and decrease central sympathetic outflow and norepinephrine release.

None of groups of the patients in the present study developed motor blockade/hemodynamic instablity [16]. Dry mouth is a known side effect of $\alpha-2$ agonists and the incidence in the present study was found more than $30 \%$ of dexmedetomidine group which is almost similar to other studies.

Goodman et al reported two case [17], larger doses (8.7 g, $9.6 \mathrm{~g}$ ) of magnesium inadvertently administered into the epidural space did not cause any neurologic injury. Also another report described an inadvertent intrathecal injection of $1000 \mathrm{mg}$ of magnesium producing a transient motor block followed by a complete resolution and no neurological deficit at long-term follow-up [18] So, when compared with these doses, our epidural dose is too low for the systemic effect.

One of the main differences of this study from ours is the route of administration and the second difference is the magnesium added with opioids or other adjuvant.

Our study has the limitation of only single dose response evaluation and epidural dose of magnesium was very small and 
Table 3: The comparison of side effects in both groups.

\begin{tabular}{|c|c|c|}
\hline Side effects & $\begin{array}{c}\text { Group D } \\
(\mathbf{N}=30)\end{array}$ & $\begin{array}{c}\text { Group M } \\
\mathbf{N}=30\end{array}$ \\
\hline Nausea \& Vomiting & 3 & 2 \\
\hline Hypotension & 22 & 0 \\
\hline Bradycardia & 15 & 0 \\
\hline Sedation (<3) & 20 & 0 \\
\hline Respiratory depression & 0 & 0 \\
\hline Dry mouth & 10 & 2 \\
\hline pruritis & 2 & 0 \\
\hline \multicolumn{2}{|c}{} \\
\hline
\end{tabular}

require large number of sample size.

This is the pioneer study which has directly compared the effects of epidurally administered dexmedetomidine and magnesium in thoracotomy.

\section{Conclusion}

Epidural Dexmedetomidine is a better neuraxial adjuvant to ropivacaine when compared to magnesium for providing prolonged post-operative analgesia and stable cardiorespiratory parameters. As other authors shown that epidural/intrathecal magnesium may be added with opioids as adjuvants for better VAS. The results of the present investigation suggest that epidural magnesium may not be a useful at small dose. Further studies should address different dosages of magnesium and different surgical procedure.

\section{Acknowledgement}

We would like to thank Dr Venkatesh Babu and staff of Institute of Medical Science, BHU for their valuable support.

\section{References}

[1]. Begon S, Pickering G, Eschalier A, Dubray C (2002) Magnesium increases morphine analgesic effect in different experimental models of pain. Anesthesiology 96(3): 627-632.

[2]. M.R. Tramer, J. Schneider, R.A. Marti, et al. (1996) Role of magnesium sulfate in postoperative analgesia Anesthesiology 84(2): 340-347.

[3]. Kroin JS, McCarthy RJ, Von Roenn N, Schwab B (2000) Magnesium sulfate potentiates morphine antinociception at the spinal level. Anesth Analg 90(4): 913-917.

[4]. Buvanendran A, McCarthy RJ, Kroin JS, Leong W (2002) Intrathecal magnesium prolongs fentanyl analgesia: a prospective, randomized, controlled trial. Anesth Analg 95(3): 661-666.
[5]. Koinig H, Wallner T, Marhofer P, Andel H (1998) Magnesium sulfate reduces intra- and postoperative analgesic requirements. Anesth Analg 87(1): 206-210.

[6]. Tramer MR, Scheneider J, Marti RA, Kaplan R (1996) Role of magnesium sulfate in postoperative analgesia. Anesthesiology 84(2): 340-347.

[7]. Kamibayashi T, Maze M (2000) Clinical uses of alpha-2 adrenergic agonists. Anaesthesiology 93(5): 1345-1349.

[8]. JC, Shafer SL, Bucklin BA, et al. (1994) Pharmacokinetics and pharmacodynamics of intraspinal dexmedetomidine in sheep. Anesthesiology 80(6): 1349-1359.

[9]. Bilir A, S. Gulec, A. Erkan and A. Ozcelik. Epidural magnesium reduces postoperative analgesic requirement. Br. J. Anaesth 98 (4): 519-523

[10]. Wider-Smith O, Arendt-Nielsen L, Gaumann D, Tassonyl E (1998) Sensory changes and pain after abdominal hysterectomy: a comparison of anaesthetic supplementation with fentanyl versus magnesium or ketamine. Anesth Analg 86(1): 95-101.

[11]. Fawcett WJ, Haxby EJ, Male DA (1999) Magnesium; physiology and pharmacology. Br J Anaesth 83(2): 302-320.

[12]. Ko SH, Lim HR, Kim DC, Han YJ, Choe H, Song HS (2001) Magnesium sulphate does not reduce postoperative analgesic requirements. Anesthesiology 95(3): 640-646.

[13]. Sirvinskas E, Laurinaitis R (2002) Use of magnesium sulfate in anesthesiology. Medicine 38(7): 147-150.

[14]. Buvanendran A, McCarthy RJ, Kroin JS, Leong W, erry P,Tuman KJ (2002) Intrathecal magnesium prolongs fentanyl analgesia: a prospective, randomized, controlled trial. Anesth Analg 95(3): 661-667.

[15]. Ozalevli M, Cetin TO, Unlugenc H, Guler T, Issk G (2005) The effect of adding intrathecal magnesium sulphate to bupivacaine-fentanyl spinal anaesthesia. Acta Anaesthesiol Scand 49(10): 1514-1519.

[16]. Bajwa SJ, Bajwa SK, Kaur J, Singh G, Arora V, Gupta S, et al. (2011) Dexmedetomidine and clonidine in epidural anaesthesia: A comparative evaluation. Indian J Anaesth 55(2): 116-121.

[17]. Kanazi GE, Aouad MT, Jabbour-Khoury SI, Al Jazzar MD, Alameddine MM, Al-Yaman R, et al. (2006) Effect of low-dose dexmedetomidine or clonidine on the characteristics of bupivacaine spinal block. Acta Anaesthesiol Scand 50(2): 222-227.

[18]. Goodman EJ, Haas AJ, Kantor GS (2006) In advertent administration of magnesium sulphate through epidural catheter: report and analysis of a drug error. Int J Obs Anesth 15(1): 63-67.

[19]. Lejuste MJ (1985) In advertent intrathecal administration of magnesium sulfate. S Afr Med J 64: 715-730. 